\title{
LOS CAZADORES DE BALLENAS EN LA LITERATURA CHILENA*
}

\author{
WHALERS IN CHILEAN LITERATURE
}

\section{ÁlVARO GUERRERO GABElLA**}

\section{RESUMEN}

Se describe y analiza las representaciones de la caza de ballenas y de la figura misma del cetáceo que la literatura chilena ha desarrollado en diversos periodos históricos, los que van desde fines del siglo diecinueve hasta la actualidad, utilizando como material de estudio a dispositivos literarios de amplio rango: narrativa, poesía, reportaje, novela gráfica, etc. El objetivo del artículo estriba en medir el cambio cultural acaecido sobre la representación de la ballenería y la ballena desde la literatura decimonónica hasta la contemporánea.

Palabras clave: Ballenería, literatura, representación, cambio cultural.

\section{ABSTRACT}

This paper describes and analyses the representations of whaling and whales in Chilean literature from the nineteenth century to the present, using a wide range of literary material such as narrative, poetry, journalism, comics, etc. The aim of this article is to understand the cultural change that took place on the representation of whaling and whales in literature in said period.

Keywords: Whaling, literature, representation, cultural change.

Recibido: 01.03.17. Aceptado: 10.06.17.

* Proyecto Fondecyt No 1140056: "Una etnografía retrospectiva de la caza de ballenas en las costas de Chile durante el siglo XIX” (2014-2017).

** Antropólogo social. Universidad Academia de Humanismo Cristiano. Santiago, Chile. Correo electrónico: aguerrerogabela@gmail.com 


\section{INTRODUCCIÓN}



ESDE LA LITERATURA el desaparecido mundo ballenero, en principio, puede dividirse en dos formas representativas: una etapa histórica en la que se le concibe como un ejercicio comercial más, dentro de las economías de pequeña, mediana o gran escala, y otra en la que, debido al impacto ecológico hasta el grado de poner en peligro de extinción a diversas especies, la ballenería, en cualquiera de sus formas, ha sido investida de un intenso sentimiento de rechazo, desarrollándose un fenómeno cultural que asocia la muerte de un cetáceo por parte de seres humanos al concepto de "asesinato". Es tarea de este artículo el rastrear y discurrir sobre ese cambio de paradigma cultural, a través de las representaciones que han aportado los escritores chilenos, tanto de los desaparecidos balleneros chilenos, como de las propias ballenas, también bastante ausentes de las costas del país, donde, según testimonios de pescadores y poblaciones aledañas a los mares de Chile, se las solía ver con cierta habitualidad.

En la literatura se suele entrecruzar el acto de la cacería con la distinción del animal perseguido, fenómeno cultural que tiende a ser tempranamente sintomático tanto de cierta preocupación por lo indiscriminado de la misma cacería, como de la admiración ante la magnitud de la épica marina observada. Hablar de balleneros literarios implica abordar dos caras: hombres y cetáceos. En el caso de estos últimos, la constante fascinación cultural que los ha rodeado puede albergar un misterio, con las implicaciones en que lo desconocido y monumental suele simbolizarse en las mentes individuales y en culturas o sociedades determinadas, como por ejemplo, en el mito mapuche que estructura el relato de Mocha Dick, novela gráfica de Martínez y Ortega: "Mocha, la madre de todas las ballenas... no solo es la custodia del alma de todos los guerreros, es ella, esa ballena, la que mantiene el equilibrio entre la tierra y el mar" (2012, p. 49). Se enfatizan las dimensiones físicas deslumbrantes, pues la más grande de las ballenas es también la madre de todas ellas, conciliando "vida" (tierra) con "muerte" (mar), donde esta última representa un espacio de transfiguración y nostalgia en una relación existencial expresada de manera circular. Al igual que aquí, donde la madre de las guardianas de los espíritus de guerreros mapuches muertos en Isla Mocha se convierte en ballena al sumergirse bajo las aguas, en Australia existe un mito de metamorfosis en que una ballena antropomorfa que se alimenta de humanos les enseña los rituales iniciáticos a los hombres de la comunidad a cambio de no ser asesinada, para finalmente abandonar la playa y, cambiando de nombre definitivamente, hundirse en el mar (Coloa- 
ne, 1995, p. 46). Cabe sí destacar que el encuentro material entre el hombre y los cetáceos se generó históricamente en el marco de su cacería, es decir, en una relación que nació y se desarrolló desde un plano de interés práctico, y si Moby Dick habría sido ambigua a la hora de empatizar con la ballenería, hermanando sutilmente "la esclavitud y la caza de la ballena" (Hoare, 2014, p. 133), en la literatura chilena, desde Baldomero Lillo a la fecha, los autores nunca se abstraen de la crueldad del "espectáculo" presenciado, aun cuando determinados contextos históricos culturales permitan usar tal epíteto, propicio a la sorpresa y la maravilla. Del abismo cultural que se abre desde la imagen de una pequeña comunidad costera que trepa por los cerros para ver el "espectáculo" de las chalupas balleneras que salen a "pescar" a mar abierto (Lillo, 1942, p. 157), hasta llegar a la imagen de Greenpeace bloqueando buques balleneros en los puertos o lanzándose a las ramplas donde se remolcan las ballenas, preguntar por la evolución del paradigma cultural en la representación de la ballenería implica dar cuenta de un deslizamiento de interés que transita de la figura del cazador, en la modernidad, a la de la ballena, su anterior "presa", en la época contemporánea (Hoare, 2014, p. 57).

Los primeros testimonios literarios de actividad ballenera en Chile con que contamos son obra de escritores de la zona del Biobío, que tenían como modelos de observación a los balleneros de Caleta Tumbes, situada a 20 kilómetros de Concepción, y de la Isla Santa María, localizada 29 kilómetros al oeste del territorio continental, justo frente a Coronel. Este tipo de tradición ballenera operaba con tripulaciones de hasta más de diez hombres a bordo de chalupas balleneras de origen estadounidense (Lillo, 1942, p. 161), o en testimonio de Diego Dublé Urrutia, manejadas por "cinco bogadores que reman sin descanso, sin hablar, comer, ni beber, como si fueran fantasmas de la mar". Tales embarcaciones trasladaban a la ballena capturada hacia la costa donde era finalmente procesada en precarias estaciones situadas junto al borde marino.

Los materiales literarios de los siglos XX y XXI son más diversos ya que comprenden, además de la narrativa y la crónica, a la poesía y el comics. Como tales, la dimensión espacial en la que los balleneros representados se mueven es más heterogénea y la aproximación a sus identidades más compleja o minuciosa. Además, el material novelesco ofrece la posibilidad de profundizar en el análisis de los sujetos, es decir, en las psicologías individuales. No contamos con retratos de los pescadores de ballenas de las caletas o islas, sí de aquellos destinados a los modernos barcos cazadores que se hacían a la mar durante días o incluso semanas.




En los escritos tempranos se suele designar la ballenería como "pesca". Esta denominación postula la imagen de la ballena como un pez, a diferencia de "caza", que comprende a la ballena dentro de las presas de caza, primordialmente terrestres. Lillo muestra a pescadores que capturan una presa denominada "monstruo", algo inusual para las ficciones de fines de siglo veinte. Tal monstruosidad, por encima de la etimología de la palabra "cetáceo", "del griego ketos, que significa monstruo marino" (Hoare, 2014, p. 42), no tendería a involucrar elementos negativos, sino más bien de una sensación de extrañamiento con la que este particular mamífero marino se presenta a ojos humanos para recordarle, tal vez, cierto cruce entre lo humano y lo incomprensible o abismal: "lo que teníamos enfrente no era una ballena sino la naturaleza misma" (Martínez y Ortega, 2012, p. 88). Dublé Urrutia (1905) titula a su crónica "La pesca de la ballena", uno de cuyos capítulos, dedicado a describir in situ la acción misma de la cacería, se titula "La cacería de la ballena", concibiendo al ballenero artesanal como un pescador, donde la "caza" del cetáceo viene a ser solo una etapa de tal oficio, "entre los pescadores libres... se distinguen principalmente los tumbinos... dedicando sus mejores energías a la persecución y beneficio del más grande de los monstruos marinos".

A mediados de siglo veinte, una diferencia fundamental entre las dos fases de la ballenería costera industrial (caza con cañón y procesamiento industrial en tierra) está afincada en la palabra "caza", para diferenciarla de la pesca y sus dinámicas propias, y si Coloane señala que "hay un instinto de cazador que se despierta extrañamente en todo hombre que va a bordo de un ballenero" (2004, p. 179), Salvador Reyes habla de una especie de sed que emerge durante la persecución: "el Alcatraz se había animado con una especie de alegre violencia... una alegría brutal le animaba, mezclada a la angustia de que la presa pudiera escapar" (1975, p. 84). Ante la insistencia de tal instinto emerge una pregunta eje en la identidad del ballenero, entre los aspectos puramente materiales y técnicos, y los de orden simbólico: “ ¿Ama el ballenero a la ballena o la odia cuando la persigue y la mata? ¡Nunca se conocerá el misterio de ese corazón humano! ¿Es solo la paga lo que lo ha determinado a afrontar esa dura y riesgosa vida?" (Coloane, 2004, p. 179). Es difícil rastrear y dilucidar una respuesta a estas preguntas para el caso de la ballenería industrial, donde el miedo parece cobrar más sentido en la pesadilla de encontrarse con un día en que no haya más ballenas que cazar, que la de sentirse vulnerable ante el antes llamado "monstruo": "Aho- 
ra las grandes ballenas se hallaban reducidas a la condición de animalillos inofensivos... al recibir la granada que el capitán dispara desde la proa de su buque, bien al abrigo de todo peligro" (Reyes, 1975, p. 48). La divergencia en la relación de poder entre el ballenero y el cetáceo agravó los grados de intensidad en la captura, la velocidad y "cantidad" necesarias para sustentar el negocio, sea representando la fase de caza, "Agriado el ánimo al mirar sus únicas tres ballenas a remolque" (Ídem, p. 190), o la terrestre industrial, la otra cara de la caza moderna costera, "La caleta del Cerezo, no alcanzaba, con sus cinco cazadores, a surtir eficientemente la planta beneficiadora" (Reyes, 1975, p. 46). Frente a este holocausto, el camino lleva directamente a las visiones contemporáneas del ballenero como agente y síntoma de corrupción y decadencia cultural que se encuentran en la novela Mundo del fin del mundo, relato de corte ecológico y romántico, donde se retratan dos tiempos y formas de cazar: una artesanal, materializada por precarios cazadores de los canales patagónicos durante la adolescencia del protagonista, y la otra, industrializada caza pelágica japonesa, formada por una flota pirata. Un factor interesante aquí es que, si bien los dos elementos de degradación cultural citados pueden representar a la antimodernidad, antónimo al desarrollo y al progreso material y mental, es justamente en el contexto de hipertecnologización de la nave japonesa "Nishin Maru" donde se posibilita el clímax pesadillesco que destruye la naturaleza a un grado tal en que solo ella misma puede llegar a defenderse por sí sola. Es la narración de una matanza de cetáceos al estilo de la caza de caballos a "la australiana", fulminados en la noche desde el aire, "esperó Tanifuji el helicóptero en Corcovado... ametrallaba ballenas que acudían curiosas a los reflectores" (Sepúlveda, 1988, p. 134). El grado de intensificación de la lógica práctica comercial devora aquí cualquier definición que la ballenería pueda recibir, cabiendo solo la pesadilla que roza lo irreal y a la vez es perfectamente factible.

\section{AVENTURAS, RIESGO, MOTIVACIONES}

Si Philip Hoare hace notar que este "sucio negocio" de la cacería de ballenas del siglo XIX llamaba la atención de los inversores dada las millonarias fortunas creadas en esta industria "globalizada", también, al resaltar las horribles condiciones que la infraestructura de los grandes balleneros ofrecía al grueso de la tripulación (2014, p. 166), expresa una idea romántica: la principal motivación para unirse a una expedición ballenera por dos o más 


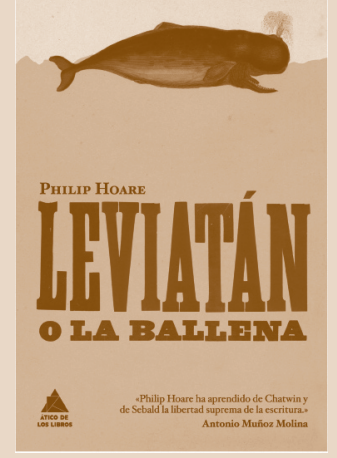

años, no sería el dinero sino la "aventura", asociada a lo lejano y exótico, y opuesta a la cercanía presencial de los grupos humanos implicados en el espectáculo riesgoso de la pesca tradicional de ballenas. En el contexto cultural del siglo XIX en Chile, los narradores conciben que el esfuerzo y riesgo laboral del modesto cazador costero no solo transitaba sobre la delgada línea de subsistencia, sino también en la exposición constante de su tipo de oficio a las exigencias del espectáculo, el poner en juego la noción de honor y estatus frente a la comunidad: "I tengamos mucho cuidado de portarnos heroicamente porque por todas las crestas de los cerros que dan a la mar, se ven correr las mujeres, los hombres i los niños que han quedado en la caleta. Van a contemplar, como desde un grandioso palco preparado por la naturaleza, la más imponente de las cazas a que obliga el hombre "la lucha por la vida", el struggle for life de Darwin" (Dublé Urrutia, 1905), y una permanente puesta en juego de las capacidades y condiciones especiales del ballenero ante sus "iguales", en especial en torno a la figura del arponero, "solo dispone de un arponazo, si lo yerra no solo queda deshonrado sino que la ignominia se extiende a la tripulación, siendo todos objeto de rechifla de chicos y grandes, el arponero por afortunado que sea en lo sucesivo no podrá hacer olvidar este fracaso mientras viva" (Lillo, 1942, p. 162). Es el trabajo visto como espectáculo y escrutinio en un solo movimiento, el evento particular elevado a la altura de mito, sea positivo o desastroso. La noción épica de este tipo de ballenería, asociada a los peligros de la caza, no impide que la fase del procesamiento en tierra pueda involucrar elementos de carácter festivo. Dublé Urrutia testimonia que "se comienza el arrastre, esta operación es fatigosísima i suele durar hasta tres o cuatro días... será este, además, un día de fiesta para la caleta", llegando al cuasi paroxismo del espectáculo y la alegría en la festividad popular, "después de algunos días entra la ballena a Tumbes entre el general entusiasmo de la jente. Largo sería describir este acto triunfal que recuerda la entrada a Roma de los cónsules de la república, seguidos por algún rei o reina bárbaros, encadenados".

La literatura contemporánea tiende a humanizar la ya tradicionalmente mitificada figura de la ballena. En Mundo del fin del mundo es difícil dilucidar lo fantástico de lo real en el relato donde las ballenas pasan a cobrar personalidad, comunitaria y resuelta, más allá de la fascinación siempre presente en la literatura por sus reacciones de supervivencia en la etapa de la caza en alta mar, "obedeciendo a una llamada que ningún otro hombre ha escuchado en la mar... una multitud de ballenas y delfines nadaron veloces hasta casi tocar la costa, para volver con mayor velocidad aún y estrellar sus cabezas contra el barco" (Sepúlveda, 1988, p. 135). Martínez y 
Ortega hacen algo similar en su novela gráfica, aunque en este caso la naturaleza del relato se ajusta perfectamente al terreno del mito, "el monstruo fue por la madre y su cría. Empujó sus cuerpos como si quisiera llevarlos a un camposanto en el mar" (2012, p. 34).

En las ficciones de Coloane y Reyes la figura del capitán emerge con fuerza por encima del grupo, protagonista en el caso de los decimonónicos, o de los cetáceos en la contemporaneidad, constituyendo retratos más complejos y acabados, incluso de tintes trágicos, al estructurarse en la ecuación trabajo igual a existencia, "no se sentía ligado ni siquiera a su tierra, a una comarca o a un país. Su patria, como la ballena, era el mar, y su futuro, lo que había más allá del horizonte marino" (Coloane, 2004, p. 254)... "Su oficio de capitán arponero tenía para él un valor independiente del lugar en que se ejercía. Julio Moreno... seguía su destino y se conformaba con los días de su vida" (Reyes, 1975, p. 277). Por encima de estas revelaciones parciales del destino u horizonte de este tipo de ballenero, surgen los detalles más habituales que lo llevan a constituirse día a día como tal, "al tomar el arma por la culata el capitán sufrió una transfiguración. Toda la tripulación tenía puestos en él sus ojos" (Coloane, 2004, p. 181). Es crucial, a este respecto, la afirmación de que los lazos que enriquecían tal tejido social a bordo, no solo se concentraban, sino que se actualizaban solo al momento de la caza, para tender a diluirse después (Ídem, p. 230). Ese tejido, que podríamos postular como conformador de una identidad o antropología del ballenero costero industrial, solo existía al momento de actualizarse el "instinto de caza", durante la persecución y muerte del cetáceo. En oposición a la búsqueda de una épica a menudo ilusoria, la idea de "aventura" resurge para el siglo veinte en un tembloroso y precario tejido social que unía y enfrentaba entre sí a los balleneros de la literatura chilena, al rechazar la vida en tierra: "No importaba de dónde, cómo y quién era el ballenero; lo importante era su contribución para dar caza a la ballena... muchos de tierra adentro creían que andaban por aventuras, pero no, andaban por una dentellada más que no habían podido dar en tierra y que la daban exponiendo sus vidas en plena mar" (Ídem, p. 231). Y la posibilidad, siempre regada de matices y conflictos, de sentirse parte de una red de trabajo muy diversa en su composición nacional, étnica, etaria, etc.: "Embarcado en Talcahuano, Chile, Leftraru decía ser descendiente de grandes guerreros Mapuche... pero sus sueños estaban en el mar, quería convertirse en un gran arponero... le enseñé a hablar inglés. Él, por su parte, me enseñó a mejorar el español" (Martínez y Ortega, 2012, p. 22). Si el mar y la ballena eran en el mito metáforas del destino y la trasfiguración espiritual, en Co-

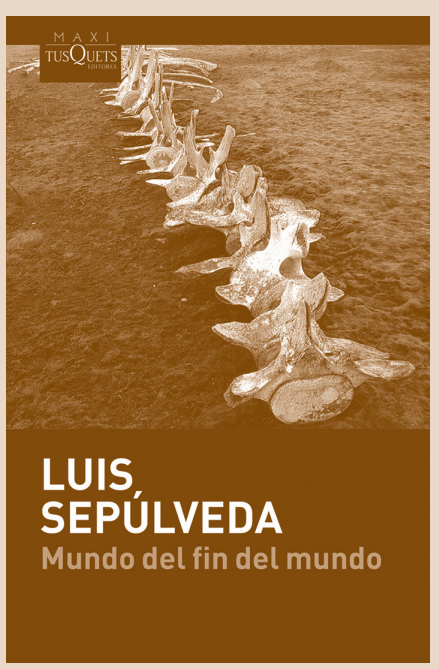

LUIS SEPULVEDA

Mundo del fin del mundo 
loane, ambos pasan a ser, entonces, el territorio simbólico de la "segunda oportunidad" en la vida, y los buques balleneros de la era de Moby Dick, en Mocha Dick, un espacio naturalizado a la heterogeneidad cultural.

\section{TEMPRANAS Y CONTEMPORÁNEAS PREOCUPACIONES ANTE LO INDISCRIMINADO DE LA CACERÍA}

La literatura decimonónica solo se oscurece al representar la ballenería con la presencia de los ballenatos o ballenas lactantes. Lillo describe una persecución en la que se debe decidir en fracción de segundos a qué objetivo arponear, optando finalmente por la cría, "una mirada les bastó para decidirse... la presencia de los amigos y parientes en la ribera y en los cerros, les enardece afirmándolos en su propósito" (1942, p. 162). Dublé Urrutia usa la palabra "asesinato", cuando, en el único momento en que su entusiasmo se nubla ante lo observado, narra un caso similar y verosímilmente frecuente, "la caza de la ballena en estas circunstancias es de veras triste de narrar... en otras ocasiones, i muy frecuentes en ciertas épocas, la hembra está embarazada i el asesinato es doble". Aquí el autor ya no llama a la ballenería, ni pesca ni caza, escenario que Lillo no concibe para representar el sentir de la expectante comunidad ballenera que describe: "pobre ballenatito, dijo la niña, que lástima le tengo. No deberían matarlo ahora... -si pudiéramos meterlo en una redoma para arponearlo cuando estuviese más crecidito, yo también lo perdonaría, mujer.- Rosenda hizo una mueca y todos soltaron la carcajada" (1942, p. 159). En estos tempranos relatos, el "espectáculo" desde los cerros cobra vigor en la siempre latente y potencialmente instantánea presencia de la muerte, o el "asesinato", sea de los balleneros, los ballenatos o las ballenas.

Los años cincuenta son de ambivalencia. A pesar de la distancia, casi rotunda, en la relación de poder entre cazador y presa, un escritor "del mar" como Salvador Reyes puede naturalizar el oficio del capitán ballenero describiéndolo como una vida "caprichosa y sacrificada" (1975, p. 48), que constituye uno de los últimos espacios de "libertad y aventura" (Ídem), distinta a "los itinerarios fijos de los vapores" (Ídem). Un diálogo de la novela complejiza tal contexto cultural a través de las visiones contrapuestas del testigo observador y el capitán, donde el primero muestra un sentimiento negativo hacia la caza, el que tendrá una evolución zigzagueante durante la travesía, desde la preocupación ante la desmesura de la persecución, "ustedes terminarán por extinguirlas” (Ídem, p. 82), pasando luego a ese 
"oscuro sentimiento de cazador" referido, para finalmente, y ya en presencia de toda la potencia y majestuosidad del animal, sufrir el impacto de la brutalidad del hecho: "los contornos de esas masas oscuras parecían pesar sobre el mundo...el horror de aniquilar esa vida inmensa, esa fuerza terrible que emergía desde el fondo del mar" (Ídem, p. 94). La fascinación ante la ballena es palpable, el testigo imparcial se ha transfigurado y "rendido", los balleneros han dejado de ser "espectáculo" ante la naturaleza: el cetáceo y su imponente, y por lo mismo inevitable, recordatorio de la precariedad de lo "vivo". Las últimas impresiones del personaje, más que convicciones éticas ante la caza, entroncan con un sentimiento existencial que produce una verdadera alucinación, la inevitable muerte de lo "vivo": "treinta o cuarenta hombres, algunos armados de enormes cuchillos ayudaban... tuvo la visión de una escena absurda en que la humanidad enloquecida aullaba y alzaba los brazos saludando su victoria sobre las fuerzas supremas de la naturaleza... ¡victoria del hombre, ya no hay más bestias en las tierras ni en los mares! ¡Máquinas, solo máquinas!... ¡hemos arrancado al mar su último habitante, el más monstruoso, el que encerraba toda la potencia del animal" (Ídem, p. 103). Para el capitán Julio Moreno, el caso no ofrecería respuestas satisfactorias: "su misión y la de sus hombres era dominar el mar y matar las ballenas; pero no podía llamar enemigos ni al mar ni a las ballenas" (Ídem, p. 257), una paradoja solo "administrable" por el contexto económico de tal dominación: "Pero nadie nos ha quitado el número de ballenas cazadas -dijo el piloto...-. Sí, pero lo que le interesa a la compañía es el tonelaje" (Coloane, 2004, p. 196).

Contemporáneamente, Mundo del fin del mundo, novela de fin de siglo, identifica dos tipos de sujetos plenamente "primitivos": los balleneros semi "artesanales" que el adolescente encuentra en su primer viaje iniciático, hombres que trabajan en un espacio de soledad e independencia alejados de cualquier tipo de proletarización en el espacio de la modernidad industrial: "La tripulación del Evangelista la integraban, además del Vasco y don Pancho, dos marinos chilotes de muy pocas palabras y un argentino que oficiaba de electricista y cocinero" (Sepúlveda, 1988, p. 34), "navegamos algunas horas por las quietas aguas del canal ballenero... la construcción de madera que dominaba la ensenada era la factoría... descubrí que aquellos troncos eran las osamentas de cientos de ballenas faenadas en la playa de piedras y conchuelas" (Ídem, p. 36), y los balleneros japoneses, contemporáneos a la adultez del personaje narrador, que simultáneamente cuentan con una compleja infraestructura técnica y la intervención política estatal y empresarial privada de la época de la dictadura (Ídem). Ambos tipos de 
balleneros parecieran escapar a cierta idea de modernidad: los primeros antecediéndola por un aislamiento geográfico y político que los revela como sobrevivientes tanto como "outsiders", y los últimos, distorsionándola técnicamente hasta el delirio antiecológico. Los cazadores del canal ballenero de Sepúlveda están en las antípodas del ballenero-espectáculo de Baldomero Lillo y Dublé Urrutia. Son dos hombres, que tras un largo viaje por geografías desoladas, cazan un cachalote (Ídem, p. 40), para, acompañados de los tres marinos, terminar de descuartizarlo y transformarlo en aceite con sus propias manos (Ídem, p. 41), en una solitaria estación de madera que quedará vacía hasta su próximo viaje, perdida entre canales patagónicos. Sus palabras de despedida están cargadas de un mundo que ya ha desaparecido y del cual son representantes fantasmales: "Me alegra de que no le haya gustado la caza. Cada día hay menos ballenas. Tal vez seamos los últimos balleneros de estas aguas, y está bien. Es hora de dejarlas en paz" (Ídem, p. 42). Declaraciones llenas de nostalgia y lucidez, contrastantes al sueño-pesadilla que el capitán japonés termina revelando como reverso anacrónico de dicha sensación finalista, "Ustedes y yo tenemos algo que nos une: somos soñadores, y mi sueño es comenzar nuevamente con la caza comercial de ballenas a gran escala" (Ídem, p. 57). Los primeros parecen vivir anacrónicamente entre el presente y el pasado, lo que se condice con la hibridación tecnológica con que practican el antiguo oficio. Mientras que el "moderno" capitán Tanifuji parece el agente de una acción imparcial ante la vuelta de la historia ya ocurrida.

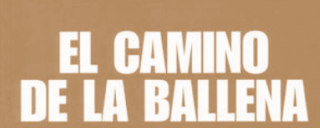

Francisco Goloane

\section{EVOLUCIONES, CONTRASTES Y DIFERENCIAS: TOMANDO A UN AUTOR COMO EJEMPLO}

En un mismo escritor la representación de ambas figuras, presa y cazador, pueden ser investidas indistintamente con la gracia de la maravilla o el entusiasmo. En "Oceanografía dispersa" Pablo Neruda nombra a los balleneros chilenos como, "los más audaces del hemisferio marino" (2010, p. 98), al tomar nota del destino final de sus viajes, "el antártico y sus cóleras" (Ídem, p. 98), idealizando a aquellos que tuvieron como territorio de acción las aguas alrededor de la isla Decepción, descritos por Coloane en $E l$ camino de la ballena. También llama "tesoros" (objetivo de los aventureros) a las materias primas obtenidas del cachalote (Ídem), "monstruo" al que a su vez ha humanizado en un párrafo anterior al dotarlo de una dimensión "nacional": "El cachalote, o ballena dentada, la más chilena de las persegui- 
das" (Ídem, p. 97). El efusivo lenguaje de Neruda al expresar sus recuerdos manifiesta el asombro del niño ante la maravilla: "es el plancton el que me interesa; esa agua nutricia, molecular y electrizada que tiñe los mares de un color de relámpago violeta. Así he llegado a saber que las ballenas se nutren casi exclusivamente de este innumerable crecimiento marino" (Ídem). Así, las ballenas son parte de la maravilla generalmente más propicia al reino de la naturaleza que al del ballenero, cazador audaz en estas páginas, y erizado de "corazones duros como arpones" (Neruda, 2014, p. 472), en "Los navíos" del Canto general, en el que forma parte de otro reino, el de los hombres comerciantes de mar (Ídem, p. 471). La emoción ante la maravilla de la ballena y la tragedia de su caza llega a niveles culminantes de épica lírica en Leviathan. Aquí la ballena se confunde con el territorio vaporoso que tiende a fundir las ideas de "creación" y "evolución" en un origen común "cuando tu sangre ciega fue fundada la edad del mar dormía en los jardines" (Ídem, p. 486), para luego manifestar la transparencia, fecundidad y sobre todo, el sentido del proceso "madre medusa, multiplicada tempestad de ovarios, y todo el crecimiento era pureza" (Ídem). La ballena es madre, sinónimo de vida en general, y a la vez es destinada a un escenario majestuoso, el de la naturaleza en nacimiento y crecimiento, debido a esa misma fuerza, "así fue tu gigante arboladura dispuesta entre las aguas como el paso de la maternidad sobre la sangre" (Ídem, p. 487). Este proceso de maternidad y creación parece perpetuarse o hacerse intemporal, como un "estado natural", hasta que es bruscamente cortado por el encuentro con el hombre "extravío y terror estremecieron la soledad, y huyó tu continente" (Ídem). Los balleneros ya no son sinónimos de audacia sino de tragedia "el terror pasó sobre los globos de la luna glacial, y entró en tu carne, agredió soledades" (Ídem). Los versos finales aluden ya directamente a la gran derrota de la ballena en su propio territorio, una zona del mundo en que los balleneros más que hombres de mar parecen invasores, elementos anacrónicos dentro de un cierto orden natural del mundo, artificios a los que no se nombra ni significa sino es por su propia creación: su 'arma', "revolviendo sus truenos derrotados en la comarca del arpón, teñido por el mar de la sangre... hasta las barcas negras de la grasa pobladas por rencor y pestilencia” (Ídem). La pureza inicial ha sido devastada por la cultura. En cierto modo, la naturaleza y la cultura se transfiguran o relacionan de distinto modo. Esta cultura ha pasado a ser lo reflejado de la naturaleza misma: "Oh gran estatua muerta en los cristales de la luna polar" (Ídem), retórica poética donde tales objetos "producidos" por el hombre, "estatua" y "cristal", se alejan de este y sus potencialidades creativas, dejándolo solitario en el sitio de la pura 


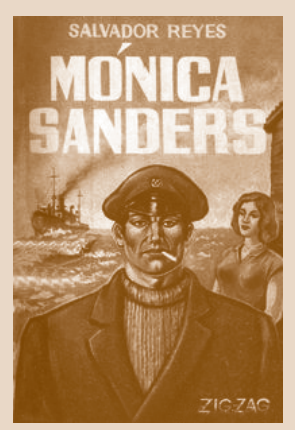

destrucción, "llenando el cielo como una nube de terror que llora y cubre los océanos de sangre" (Ídem), revelación que conecta directamente con las citadas divagaciones del periodista testigo en Mónica Sanders: "Pondremos en el corazón del universo nuestro explosivo más potente y, aniquilándonos al fin nosotros mismos, habremos conquistado nuestra victoria suprema sobre la vida" (Reyes, 1975, p. 103).

La ballena como imagen y concepto ya funciona en tiempos anteriores a los movimientos ecológicos y a la conciencia de la puesta en peligro de especies completas por la indiscriminada cacería industrial, como un símbolo de lo que el ser humano hace, y se hace a sí mismo: la autodestrucción.

\section{CONCLUSIONES}

En la literatura chilena de fines del siglo XIX el ballenero se concibe como un pescador, aun resaltando su singular instinto cazador que guarda como principal atributo y potencial para practicar el oficio, y que es, además, consustancial a los relatos y representaciones literarias universales sobre la ballenería. Para la mentalidad decimonónica adentrarse en el mar y enfrentarse a enormes mamíferos marinos comporta un "espectáculo" en sí, no solo para el testigo externo, sino para la comunidad involucrada. El ballenero, entonces, es entendido como un pescador excepcional, dada la distinción de su presa. La fascinación ante el mundo de la ballenería persiste en la literatura durante el siglo XX, al encontrar referencias y representaciones acabadas de balleneros en escritores como Francisco Coloane, Salvador Reyes y Pablo Neruda, escritores con una fuerte resonancia hacia mundos que posibiliten la reunión o el enfrentamiento del hombre con la naturaleza. El mundo ballenero sigue siendo representado con naturalidad. Emergen sí, en el siglo XX, sombras derivadas de la preocupación por la indiscriminada y escasamente regulada práctica ballenera que ahora es llamada directamente "caza". El ballenero literario ahora, ayudado por la minuciosa descripción del género novelesco, no depende tanto de la exaltación de la figura de la ballena para erigirse como personaje excepcional del espacio marino. Su representación transita constantemente entre el profesionalismo que emerge del grupo de trabajo mancomunado durante la persecución, y el drama social y existencial, deudor de condiciones de trabajo aisladas de la civilización y las normas y hábitos de vida considerados como habituales. Tal idea de "libertad" del oficio ballenero en las grandes compañías privadas comporta siempre elementos negativos o contradictorios, insinuándose un 
fenómeno incipiente de decadencia en la industria misma, una despedida anticipada de un mundo que comienza a apagarse. En este retablo la figura de la ballena, monstruo marino, depósito de mitos, pasa a un segundo plano, a la vez que es entendida cada vez más como víctima, es decir, como un habitante del mar que no puede catalogarse fácilmente, incluyéndolo dentro de la pesca y sus objetivos de presa.

Ante el cambio de reglas tecnológicas ocurrido en el violento encuentro hombre-cetáceo, en la literatura contemporánea la figura de la ballena evoluciona al grado de contar con personalidad e incluso raciocinio, pero a diferencia de la presencia omnipotente del mal en la ballena blanca de Moby Dick, esta vez los cetáceos alcanzan un verdadero grado de humanismo, expresado tanto en defensa de su integridad como individuos y como grupo "social", simbolizando transfiguraciones del destino del propio ser humano, como ideales de una naturaleza perdida, en parte espejos más "limpios" donde mirarse. En estas ficciones contemporáneas los precarios balleneros semiartesanales chilenos, como los clásicos balleneros norteamericanos de las expediciones por el Pacífico sur, pueden recibir un dejo de admiración o respeto ante un mundo desaparecido en el que el "cazador" perseguía al cetáceo mirándolo más bien hacia arriba, al ver acercarse su cola o su costado, como una loma ondeando entre las aguas. El paso de la figura de esos balleneros a aquellos que ordenan ametrallar ballenas desde el aire puede referirse a la misma dinámica del comercio mundial y la evolución industrial y tecnológica ocurrida durante el siglo veinte. Cabe preguntarse si la intensificación de la lógica capitalista en la ballenería puede llevar a largo plazo directamente a esa "masacre a la australiana", o simplemente al holocausto que sufrieron especies completas de cetáceos. Es decir, qué puede haber de tal lógica, insipientemente ya, en el muy citado "instinto cazador", y qué definitivamente no hay. En la contemporaneidad literaria hay un dejo de admiración o pequeño homenaje a los antiguos balleneros y un horror ante aquellos de la era industrial. Sería hoy impensado crear representaciones de balleneros como las publicadas hasta los años sesenta, donde se reafirma la idea del oficio ballenero como espacio de "libertad" y, aun, de "aventura". Cambiando la pregunta de Coloane, no tiene sentido, ni probablemente lo habría tenido en el momento de su publicación, el preguntarse si "ama u odia el ballenero a la ballena cuando la ametralla desde el aire”. El cazador de mamíferos sería abandonado por la antigua relación naturaleza-cultura cuando la mínima ética del encuentro cara a cara con el "monstruo" se distorsiona en el cambio de perspectiva ante ese "monstruo". En esta relación hombre-ballena como metáfora de la cultura frente a la 
naturaleza el ballenero entra y sale de la naturaleza en función del instinto de caza (relación simbiótica: naturaleza, pulsiones-cultura) y su evolución dependiendo de los contextos históricos y el cambio en los medios técnicos de la ballenería. Puede haber una lucha (dominación brutal) por la significación de una naturaleza desconocida, monstruosa, maravillosa, todo a un solo tiempo.

Tal vez estudiar la evolución histórica de la representación del ballenero conlleva preguntarse por el cambio en la relación del hombre con su medio natural, del fenómeno progresivo de un extrañamiento del ser humano como parte de la naturaleza, allí donde el cambio de reglas técnicas o su intensificación industrial a niveles catastróficos puede comportar la transfiguración del "cazador" en "criminal" o, simplemente, en el fenómeno de una "artificialización" del "instinto de caza" acomodado en la conciencia de la "seguridad", "eficiencia" y "velocidad" que pasan a ofrecer los marcos tecnológicos a los balleneros del pasado siglo.

El hombre, al destruir con la mayor eficacia técnica posible, se autodestruye, aislándose de la naturaleza al dejar de ser agente de producción cultural, primando solo la técnica como un emblema ondeando tanto en el pasado como en el horizonte.

\section{REFERENCIAS}

Coloane, F. (1995). Velero anclado. Santiago, Chile: Lom Ediciones.

Coloane, F. (2004). El camino de la ballena. Santiago, Chile: Lom Ediciones.

Dublé Urrutia, D. (1905, febrero 5). "La pesca de la ballena”. El Sur (Concepción).

Hoare, P. (2014). Leviatán o la ballena. Barcelona: Ático de los libros. Lillo, B. (1942). Relatos populares. Santiago, Chile: Nascimiento.

Martínez, G. y Ortega, F. (2012). Mocha Dick. Santiago, Chile: Norma. Neruda, P. (2010). Confieso que he vivido. Barcelona: Seix Barral.

Neruda, P. (2014). Canto general. Santiago, Chile: Pehuén.

Reyes, S. (1975). Mónica Sanders. Santiago, Chile: Zig-Zag.

Sepúlveda, L. (1988). Mundo del fin del mundo. Barcelona: Tusquets. 